\title{
Unraveling the crucial roles of Meis1 in leukemogenesis and normal hematopoiesis
}

\author{
Bob Argiropoulos, ${ }^{1}$ Eric Yung, ${ }^{1}$ and R. Keith Humphries ${ }^{1,2,3}$ \\ ${ }^{1}$ Terry Fox Laboratory, British Columbia Cancer Agency, Vancouver, British Columbia, Canada; ${ }^{2}$ Department of Medicine, \\ University of British Columbia, Vancouver, British Columbia, Canada
}

The "cancer stem cell" hypothesis has emerged as the leading paradigm in how we view the origin and perpetuation of neoplastic-initiating cells in leukemia and solid tumors (for review, see Buzzeo et al. 2007). Central to this model is the concept that only a rare subpopulation of cells in the malignant clone retains or acquires the ability to self-renew and proliferate to initiate and maintain the disease. Although hematopoietic stem cells (HSC) with inherent self-renewal properties are generally believed to be the initiating cells for malignant transformation in acute leukemias, it is now evident that the target stem cell of origin for select oncogenic mutations includes committed hematopoietic progenitors. While substantial evidence supports a leukemic stem cell (LSC) model in both acute myeloid and chronic leukemias, details of the molecular processes regulating LSC properties remain poorly resolved. Insights into these processes have recently emerged from recognition that many key regulators of HSCs and LSCs are transcription factors, as evidenced by their obligatory expression in normal primitive hematopoietic cells and/or their involvement in leukemia-specific translocations.

Chromosomal translocations involving the Mixed Lineage Leukemia $(M L L)$ gene (11q23) fuse N-terminal sequences of $M L L$ to one of $>40$ functionally diverse group of C-terminal fusion partners (Daser and Rabbitts 2005) and constitute $5 \%$ of all acute myeloid leukemia (AML) cases and $22 \%$ of those with acute lymphoblastic leukemia (ALL) (De Braekeleer et al. 2005). Leukemias associated with $M L L$ rearrangements generally have a poor prognosis and are associated with poor response to chemotherapy (Eguchi et al. 2005). Gene expression analyses of all types of $M L L$ fusion-associated leukemias revealed HOX gene dysregulation (Rozovskaia et al. 2001; Armstrong et al. 2002; Yeoh et al. 2002; Ferrando et al. 2003), implicating $H O X$ genes as integral factors in $M L L$ fusion-associated leukemias. This is not surprising, as both wild-type MLL and MLL oncogenic fusions directly bind

${ }^{3}$ Corresponding author.

E-MAIL khumphri@bccrc.ca; FAX (604) 877-0712.

Article is online at http://www.genesdev.org/cgi/doi/10.1101/gad.1619407. to regulatory regions within Hox gene clusters and maintain the active transcription state of these genes ( $\mathrm{Yu}$ et al. 1995, 1998; Milne et al. 2005; Caslini et al. 2007). Furthermore, coactivation of HOXA9 with the HOX cofactor MEIS1 is a frequent occurrence in leukemias associated with $M L L$ rearrangements (Yeoh et al. 2002; Kohlmann et al. 2003; Tsutsumi et al. 2003; Fine et al. 2004), and may represent a common molecular pathway that unifies the oncogenic potential of these diverse MLL fusion genes. Indeed, Meis1 is also a transcriptional target of select MLL oncoproteins (Milne et al. 2005) and co-overexpression of HoxA9 and Meis1 in murine bone marrow (BM) can recapitulate $M L L$-ENL-induced immortalization of myeloid progenitor cells (Zeisig et al. 2004).

The crucial role of Meis1 in $M L L$-induced leukemia

In the previous issue of Genes \& Development, Wong et al. (2007) used various genetic techniques to examine the requirement and contribution of Meis1, and additional TALE family members-Pbx1, $P b x 2$, and $P b x 3$-in MLL-induced AML. The initial observation that the transforming potential of a broad range of $M L L$ fusion genes strongly correlates with their capacity to induce endogenous Meis1 transcription is intriguing and provided the impetus to assess the role of Meis1 in MLL oncogenesis. Using the Meis1 knockout model, knockdown of Meis1 by short hairpin RNA (shRNA) and interference of wild-type MEIS1 activity by dominantnegative genetic techniques, Wong et al. (2007) present convincing evidence that the ability of a panel of MLL fusion proteins to induce and maintain the transformation of primary murine progenitors, as measured by colony formation in vitro and leukemia in mice, is dependent and rate-limited by Meis1, and is codependent on the redundant contributions of $P b \times 2$ and $P b x 3$, but not $P b x 1$.

\section{Meis1 is a potent collaborative gene in leukemia}

Meis1 was first identified as a common viral integration site in myeloid leukemic cells of BXH-2 mice (Moskow 
et al. 1995). The importance of MEIS1 in human leukemogenesis was underscored by the finding that it was frequently up-regulated in primary AML and ALL samples (Kawagoe et al. 1999; Rozovskaia et al. 2001; Imamura et al. 2002). We and others have subsequently demonstrated that overexpression of Meis1 synergizes with multiple native and NUP98-HOX fusion genes to accelerate the onset of AML in murine BM transplantation models (Kroon et al. 1998, 2001; Calvo et al. 2002; Pineault et al. 2003, 2004; Fischbach et al. 2005). Curiously, wild-type Meis1 has no transforming activity alone, but can be engineered to do so when fused to the transactivating domain of VP16 (Mamo et al. 2006; Wang et al. 2006), thus linking its oncogenicity to transcriptional activation of its downstream target genes.

The molecular mechanisms underlying the oncogenicity of Meis1 are not fully understood. Homeodomaincontaining HOX cofactors, like MEIS1 and PBX1, alter HOX-DNA-binding specificity, increase HOX-DNAbinding affinity and augment the transcriptional activity of their constituent protein complexes. Indeed, MEIS1 and HOXA9 form dimeric DNA-binding complexes in myeloid cells (Shen et al. 1997), as well as trimeric complexes containing the HOX cofactor, PBX1 (Shen et al. 1999). Thus, as suggested for HoxA9-mediated transformation of myeloid progenitors, Meis 1 collaborates with Hox genes through the cooperative role of MEIS1-PBX1HOX complexes. Consistent with this hypothesis, Wong et al. (2007) and previous studies have demonstrated that MEIS1 requires the PBX interaction domain, presumably for interaction with PBX2 and PBX3, the homeodomain as well as the transactivating $\mathrm{C}$-terminal domain to collaborate with HoxA9 (Wang et al. 2005; Mamo et al. 2006). This hypothesis, however, does not account for the fact that NUP98-HOXD13 (ND13), lacking both PBX1 and MEIS1 interaction domains, strongly collaborates with Meis1 (Pineault et al. 2003). Moreover, ND13 strongly collaborates with MEIS1 ${ }^{\text {N51s }}$, a DNA-bindingimpaired form of MEIS1 (Pineault et al. 2005), while HoxA9 does not (Wang et al. 2005), indicating homeodomain-dependent and -independent MEIS1 activities. Interestingly, the existence of homeodomain-less MEIS1 isoforms have been identified in vertebrates of which the significance is unknown (Noro et al. 2006). These mechanistic differences illustrate the complex modular nature of MEIS1, the multiple pathways in which it can be recruited to its target genes, and underscore the potential dissimilarities in how it may mediate leukemia depending on the nature of the collaborating events.

\section{On the road to uncovering the molecular mechanisms underlying Meis1 function}

To further explore potential molecular mechanisms underlying the function of Meis1 in LSC progression, Wong et al. (2007) examined the cell cycle profiles of explanted $M L L / M e i s 1$ leukemic cells and measured the transcript levels of known cell cycle regulators. While revealing a modest and indirect connection with the RB pathway, including the HSC and LSC stem cell renewal factor
$B m i-1$, this study is limited to known factors previously demonstrated to be involved in HSC and LSC biology. Studies to identify and characterize Meis1 target genes in MLL-associated leukemia will likely prove crucial to obtaining additional molecular insight into the regulatory networks controlled by Meis 1 .

In this regard, it is of interest that the collaborative effect of Meis1 in HoxA9 and NUP98-HOX models of AML has been linked to the up-regulation of FMS-like tyrosine kinase 3 (Flt3) (Wang et al. 2005; Palmqvist et al. 2006), a receptor tyrosine kinase oncoprotein that is frequently mutated, and often up-regulated with HOXA9 and MEIS1, in human AML (Quentmeier et al. 2004). In addition to the finding that Flt3 is a major downstream effector of the leukemic collaboration of Hox with Meis1, we showed that wild-type Flt3 is sufficient to collaborate with NUP98-HOX fusion genes to induce AML. Interestingly, the development of leukemia observed with Flt3 as a collaborating gene was significantly longer compared with Meis1, suggesting that Meis1 triggers additional pathways to accelerate leukemia development. This result is corroborated by independent lines of evidence demonstrating the dispensability of Flt3 to the oncogenic cooperation of Meis1 with Hoxa9 (Morgado et al. 2007) or NUP98-HOX fusions (our unpublished data).

Gene expression analyses have been performed with microarrays to identify the Meis1 transcriptome in the Hoxa9 model of AML (Wang et al. 2005, 2006; Hess et al. 2006). These studies have identified a "Meis1 genetic signature" that includes genes previously implicated in stem cell function. Among the most interesting genes are $C d 34$, a proniche homing cell surface receptor, and Erg, a transcriptional activator of the Ets proto-oncogene family. The $c-M y b$ proto-oncogene was also activated upon overexpression of HoxA9 and Meis1, and was shown to be required, but not sufficient, for HoxA9/ Meis1-mediated leukemogenesis (Hess et al. 2006). Further functional characterization and identification of additional Meis1 target genes will undoubtedly shed light on the molecular mechanisms of Meis1 leukemogenesis.

\section{The role of Meis1 in normal hematopoiesis}

While this current study illustrates the critical influence of Meis1 on MLL LSCs, the role of Meis1 in normal hematopoiesis remains unclear. In recent years, investigations into the origin of LSCs have revealed that these cells are strikingly similar to normal HSCs, with respect to their ability to self-renew, cell surface markers, and differentiation capacities (Blair et al. 1998; Miyamoto et al. 2000; Hope et al. 2004; Taussig et al. 2005). Thus, in light of the current study, it is conceivable and likely most probable that Meis1 plays a pivotal role in normal HSC biology as well. Several additional lines of evidence indicate that this may be the case. First, Meis1, along with Hox genes, are coexpressed in the most primitive hematopoietic subpopulations and are down-regulated following differentiation (Imamura et al. 2002; Pineault et al. 2002). Second, Meis1-deficient mice die by embry- 
onic day 14.5 , presenting with extensive hemorrhaging due to the lack of megakaryocytes (Hisa et al. 2004). While definitive myeloerythroid lineages are present in these embryos, the total numbers of colony-forming cells are significantly reduced. Meis $1^{-/-}$fetal liver cells fail to radioprotect lethally irradiated recipient mice and they compete poorly in repopulation assays even though they support the formation of all hematopoietic lineages. It is possible that gene redundancy among the closely related Meis family members may compensate for the loss of Meis1, and thus may prevent the complete abrogation of HSC activity in these mice. Taken together, these studies provide strong support for the hypothesis that Meis1 plays an important role in the HSC self-renewal/proliferation. Future studies to delineate the function of Meis1 in normal hematopoiesis will provide additional molecular insights into the biology of stem cell self-renewal and will identify critical pathways for LSC formation.

\section{Meis1: a force to be reckoned with}

While the synergy between Meis1 and Hox or NUP98$H O X$ fusion genes has been extensively documented, the dependency of Meis1 in leukemic transformation, as shown in the present study for MLL-associated leukemias, was not previously appreciated. Several important questions emerge from this study. Is the initiation or maintenance of other leukemias dependent on Meis1 function? Meis1 is oncogenic by virtue of overexpression rather than mutation (MEIS1 mutations have yet to be identified in human leukemias). Thus, what cells within the hematopoietic hierarchy are susceptible to Meis1 overexpression and what cells are dependent on Meis1 activity? From the current study, it is evident that myeloid progenitors are the target cells for MLL-induced transformation but, more importantly, the transforming potential of the MLL oncoproteins tested was Meis1 dependent at this stage. Furthermore, in the case of $M L L$ AF9, the highest inducer of Meis1 expression in the current study, leukemia was initiated in myeloid cells distal to the committed progenitors (Somervaille and Cleary 2006).

\section{Meis1: a knockout punch for leukemia}

In the recent past, many regulators of HSC and LSC selfrenewal have been identified (e.g., Bmi1, Z $f_{X}$, Pten, Mcl1, Tel/Etv6, Gfi1, and Stat5). These genes, which now include Meis1, may represent the "Achilles' heel" of LSCs. Indeed, the study on Meis 1 reported in the previous issue (Wong et al. 2007) and previous studies showing the critical requirement for Bmi1 (Lessard and Sauvageau 2003; Iwama et al. 2004) in LSC function suggest that the development of tools to inhibit these regulators, or their downstream targets, may have enormous therapeutic implications. With respect to Meis1, elucidation of the molecular mechanisms involved in its activity, the potential to target MEIS1 to suppress its oncogenic activ- ity, and identification of MEIS1 target genes seems likely to shed light into the basic processes involved in the progression of MLL-associated leukemia as well as in normal hematopoiesis. Indeed, it is interesting to speculate that the dependency of MLL-associated leukemias on Meis 1 may actually extend to a broader range of leukemias. While obvious candidates include those linked to Hox deregulation or HOX translocations, it is possible that, because of the apparent essential role of Meis1 in normal HSC function, any leukemia arising directly from HSC may continue to be dependent on Meis1 function. The demonstration of the strict dependence and rate-limiting nature of Meis1 on MLL-induced AML provides the impetus to explore Meis1 and/or Pbx2 and $P b \times 3$ as potential targets for therapeutic intervention in AML. Selective inhibition and/or depletion of these factors could compromise LSC self-renewal and, thus, merits further development for the possible treatment of AML and other Meis1-expressing malignancies.

\section{Acknowledgments}

We apologize to authors whose work could not be cited due to space constraints. We acknowledge all members of our laboratory for stimulating discussions. We also thank Kim Gall for critical reading of the manuscript. Our work cited is supported by grants from the National Cancer Institute of Canada, with funds from the Terry Fox Foundation, Genome Canada/BC, and the Canadian NCE Stem Cell Network. B.A. is a recipient of a post-doctoral fellowship from the Leukemia Research Fund of Canada. E.Y. is a recipient of post-doctoral fellowships from the Michael Smith Foundation and the Canadian Institute of Health Research.

\section{References}

Armstrong, S.A., Staunton, J.E., Silverman, L.B., Pieters, R., den Boer, M.L., Minden, M.D., Sallan, S.E., Lander, E.S., Golub, T.R., and Korsmeyer, S.J. 2002. MLL translocations specify a distinct gene expression profile that distinguishes a unique leukemia. Nat. Genet. 30: 41-47.

Blair, A., Hogge, D.E., and Sutherland, H.J. 1998. Most acute myeloid leukemia progenitor cells with long-term proliferative ability in vitro and in vivo have the phenotype CD $34^{+} /$ CD71-/HLA-DR. Blood 92: 4325-4335.

Buzzeo, M.P., Scott, E.W., and Cogle, C.R. 2007. The hunt for cancer-initiating cells: A history stemming from leukemia. Leukemia 21: 1619-1627.

Calvo, K.R., Sykes, D.B., Pasillas, M.P., and Kamps, M.P. 2002. Nup98-HoxA9 immortalizes myeloid progenitors, enforces expression of Hoxa9, Hoxa7 and Meis1, and alters cytokinespecific responses in a manner similar to that induced by retroviral co-expression of Hoxa9 and Meis1. Oncogene 21: 4247-4256.

Caslini, C., Yang, Z., El-Osta, M., Milne, T.A., Slany, R.K., and Hess, J.L. 2007. Interaction of MLL amino terminal sequences with menin is required for transformation. Cancer Res. 67: 7275-7283.

Daser, A. and Rabbitts, T.H. 2005. The versatile mixed lineage leukaemia gene MLL and its many associations in leukaemogenesis. Semin. Cancer Biol. 15: 175-188.

De Braekeleer, M., Morel, F., Le Bris, M.J., Herry, A., and DouetGuilbert, N. 2005. The MLL gene and translocations involv- 
ing chromosomal band 11q23 in acute leukemia. Anticancer Res. 25: 1931-1944.

Eguchi, M., Eguchi-Ishimae, M., and Greaves, M. 2005. Molecular pathogenesis of MLL-associated leukemias. Int. J. Hematol. 82: 9-20.

Ferrando, A.A., Armstrong, S.A., Neuberg, D.S., Sallan, S.E., Silverman, L.B., Korsmeyer, S.J., and Look, A.T. 2003. Gene expression signatures in MLL-rearranged T-lineage and Bprecursor acute leukemias: Dominance of HOX dysregulation. Blood 102: 262-268.

Fine, B.M., Stanulla, M., Schrappe, M., Ho, M., Viehmann, S., Harbott, J., and Boxer, L.M. 2004. Gene expression patterns associated with recurrent chromosomal translocations in acute lymphoblastic leukemia. Blood 103: 1043-1049.

Fischbach, N.A., Rozenfeld, S., Shen, W., Fong, S., Chrobak, D., Ginzinger, D., Kogan, S.C., Radhakrishnan, A., Le Beau, M.M., Largman, C., et al. 2005. HOXB6 overexpression in murine bone marrow immortalizes a myelomonocytic precursor in vitro and causes hematopoietic stem cell expansion and acute myeloid leukemia in vivo. Blood 105: 1456-1466.

Hess, J.L., Bittner, C.B., Zeisig, D.T., Bach, C., Fuchs, U., Borkhardt, A., Frampton, J., and Slany, R.K. 2006. c-Myb is an essential downstream target for homeobox-mediated transformation of hematopoietic cells. Blood 108: 297-304.

Hisa, T., Spence, S.E., Rachel, R.A., Fujita, M., Nakamura, T. Ward, J.M., Devor-Henneman, D.E., Saiki, Y., Kutsuna, H., Tessarollo, L., et al. 2004. Hematopoietic, angiogenic and eye defects in Meis1 mutant animals. EMBO J. 23: 450-459.

Hope, K.J., Jin, L., and Dick, J.E. 2004. Acute myeloid leukemia originates from a hierarchy of leukemic stem cell classes that differ in self-renewal capacity. Nat. Immunol. 5: 738743.

Imamura, T., Morimoto, A., Takanashi, M., Hibi, S., Sugimoto, T., Ishii, E., and Imashuku, S. 2002. Frequent co-expression of HoxA9 and Meis1 genes in infant acute lymphoblastic leukaemia with MLL rearrangement. Br. J. Haematol. 119: 119-121.

Iwama, A., Oguro, H., Negishi, M., Kato, Y., Morita, Y., Tsukui, H., Ema, H., Kamijo, T., Katoh-Fukui, Y., Koseki, H., et al. 2004. Enhanced self-renewal of hematopoietic stem cells mediated by the polycomb gene product Bmi-1. Immunity 21: $843-851$.

Kawagoe, H., Humphries, R.K., Blair, A., Sutherland, H.J., and Hogge, D.E. 1999. Expression of HOX genes, HOX cofactors, and MLL in phenotypically and functionally defined subpopulations of leukemic and normal human hematopoietic cells. Leukemia 13: 687-698.

Kohlmann, A., Schoch, C., Schnittger, S., Dugas, M., Hiddemann, W., Kern, W., and Haferlach, T. 2003. Molecular characterization of acute leukemias by use of microarray technology. Genes Chromosomes Cancer 37: 396-405.

Kroon, E., Krosl, J., Thorsteinsdottir, U., Baban, S., Buchberg, A.M., and Sauvageau, G. 1998. Hoxa9 transforms primary bone marrow cells through specific collaboration with Meisla but not Pbx1b. EMBO J. 17: 3714-3725.

Kroon, E., Thorsteinsdottir, U., Mayotte, N., Nakamura, T., and Sauvageau, G. 2001. NUP98-HOXA9 expression in hemopoietic stem cells induces chronic and acute myeloid leukemias in mice. EMBO J. 20: 350-361.

Lessard, J. and Sauvageau, G. 2003. Bmi-1 determines the proliferative capacity of normal and leukaemic stem cells. $\mathrm{Na}$ ture 423: 255-260.

Mamo, A., Krosl, J., Kroon, E., Bijl, J., Thompson, A., Mayotte, N., Girard, S., Bisaillon, R., Beslu, N., Featherstone, M., et al. 2006. Molecular dissection of Meis1 reveals 2 domains required for leukemia induction and a key role for Hoxa gene activation. Blood 108: 622-629.

Milne, T.A., Martin, M.E., Brock, H.W., Slany, R.K., and Hess, J.L. 2005. Leukemogenic MLL fusion proteins bind across a broad region of the Hox a9 locus, promoting transcription and multiple histone modifications. Cancer Res. 65: 1136711374 .

Miyamoto, T., Weissman, I.L., and Akashi, K. 2000. AML1/ ETO-expressing nonleukemic stem cells in acute myelogenous leukemia with 8;21 chromosomal translocation. Proc. Natl. Acad. Sci. 97: 7521-7526.

Morgado, E., Albouhair, S., and Lavau, C. 2007. Flt3 is dispensable to the Hoxa9/Meis1 leukemogenic cooperation. Blood 109: 4020-4022.

Moskow, J.J., Bullrich, F., Huebner, K., Daar, I.O., and Buchberg, A.M. 1995. Meis1, a PBX1-related homeobox gene involved in myeloid leukemia in BXH-2 mice. Mol. Cell. Biol. 15: 5434-5443.

Noro, B., Culi, J., McKay, D.J., Zhang, W., and Mann, R.S. 2006. Distinct functions of homeodomain-containing and homeodomain-less isoforms encoded by homothorax. Genes \& Dev. 20: 1636-1650.

Palmqvist, L., Argiropoulos, B., Pineault, N., Abramovich, C., Sly, L.M., Krystal, G., Wan, A., and Humphries, R.K. 2006 The Flt3 receptor tyrosine kinase collaborates with NUP98HOX fusions in acute myeloid leukemia. Blood 108: 10301036.

Pineault, N., Helgason, C.D., Lawrence, H.J., and Humphries, R.K. 2002. Differential expression of Hox, Meis1, and Pbx1 genes in primitive cells throughout murine hematopoietic ontogeny. Exp. Hematol. 30: 49-57.

Pineault, N., Buske, C., Feuring-Buske, M., Abramovich, C., Rosten, P., Hogge, D.E., Aplan, P.D., and Humphries, R.K. 2003. Induction of acute myeloid leukemia in mice by the human leukemia-specific fusion gene NUP98-HOXD13 in concert with Meis1. Blood 101: 4529-4538.

Pineault, N., Abramovich, C., Ohta, H., and Humphries, R.K. 2004. Differential and common leukemogenic potentials of multiple NUP98-Hox fusion proteins alone or with Meis1. Mol. Cell. Biol. 24: 1907-1917.

Pineault, N., Abramovich, C., and Humphries, R.K. 2005. Transplantable cell lines generated with NUP98-Hox fusion genes undergo leukemic progression by Meis1 independent of its binding to DNA. Leukemia 19: 636-643.

Quentmeier, H., Dirks, W.G., Macleod, R.A., Reinhardt, J., Zaborski, M., and Drexler, H.G. 2004. Expression of HOX genes in acute leukemia cell lines with and without MLL translocations. Leuk. Lymphoma 45: 567-574.

Rozovskaia, T., Feinstein, E., Mor, O., Foa, R., Blechman, J., Nakamura, T., Croce, C.M., Cimino, G., and Canaani, E. 2001. Upregulation of Meis1 and HoxA9 in acute lymphocytic leukemias with the $\mathrm{t}(4: 11)$ abnormality. Oncogene 20: 874-878.

Shen, W.F., Montgomery, J.C., Rozenfeld, S., Moskow, J.J., Lawrence, H.J., Buchberg, A.M., and Largman, C. 1997. AbdB-like Hox proteins stabilize DNA binding by the Meis1 homeodomain proteins. Mol. Cell. Biol. 17: 6448-6458.

Shen, W.F., Rozenfeld, S., Kwong, A., Kömüves, L.G., Lawrence, H.J., and Largman, C. 1999. HOXA9 forms triple complexes with PBX2 and MEIS1 in myeloid cells. Mol. Cell. Biol. 19: 3051-3061.

Somervaille, T.C. and Cleary, M.L. 2006. Identification and characterization of leukemia stem cells in murine MLL-AF9 acute myeloid leukemia. Cancer Cell 10: 257-268.

Taussig, D.C., Pearce, D.J., Simpson, C., Rohatiner, A.Z., Lister, T.A., Kelly, G., Luongo, J.L., Danet-Desnoyers, G.A., and Bonnet, D. 2005. Hematopoietic stem cells express multiple 
myeloid markers: Implications for the origin and targeted therapy of acute myeloid leukemia. Blood 106: 4086-4092.

Tsutsumi, S., Taketani, T., Nishimura, K., Ge, X., Taki, T., Sugita, K., Ishii, E., Hanada, R., Ohki, M., Aburatani, H., et al. 2003. Two distinct gene expression signatures in pediatric acute lymphoblastic leukemia with MLL rearrangements. Cancer Res. 63: 4882-4887.

Wang, G.G., Pasillas, M.P., and Kamps, M.P. 2005. Meis1 programs transcription of FLT3 and cancer stem cell character, using a mechanism that requires interaction with $\mathrm{Pbx}$ and a novel function of the Meis1 C-terminus. Blood 106: 254264.

Wang, G.G., Pasillas, M.P., and Kamps, M.P. 2006. Persistent transactivation by meis1 replaces hox function in myeloid leukemogenesis models: Evidence for co-occupancy of meis1-pbx and hox-pbx complexes on promoters of leukemia-associated genes. Mol. Cell. Biol. 26: 3902-3916.

Wong, P., Iwasaki, M., Somervaille, T.C.P., So, C.W.E., and Cleary, M.L. 2007. Meis1 is an essential and rate-limiting regulator of $M L L$ leukemia stem cell potential. Genes \& Dev. 21: 2762-2774.

Yeoh, E.J., Ross, M.E., Shurtleff, S.A., Williams, W.K., Patel, D., Mahfouz, R., Behm, F.G., Raimondi, S.C., Relling, M.V., Patel, A., et al. 2002. Classification, subtype discovery, and prediction of outcome in pediatric acute lymphoblastic leukemia by gene expression profiling. Cancer Cell 1: 133-143.

Yu, B.D., Hess, J.L., Horning, S.E., Brown, G.A., and Korsmeyer, S.J. 1995. Altered Hox expression and segmental identity in Mll-mutant mice. Nature 378: 505-508.

Yu, B.D., Hanson, R.D., Hess, J.L., Horning, S.E., and Korsmeyer, S.J. 1998. MLL, a mammalian trithorax-group gene, functions as a transcriptional maintenance factor in morphogenesis. Proc. Natl. Acad. Sci. 95: 10632-10636.

Zeisig, B.B., Milne, T., Garcia-Cuellar, M.P., Schreiner, S., Martin, M.E., Fuchs, U., Borkhardt, A., Chanda, S.K., Walker, J., Soden, R., et al. 2004. Hoxa9 and Meis1 are key targets for MLL-ENL-mediated cellular immortalization. Mol. Cell. Biol. 24: 617-628. 


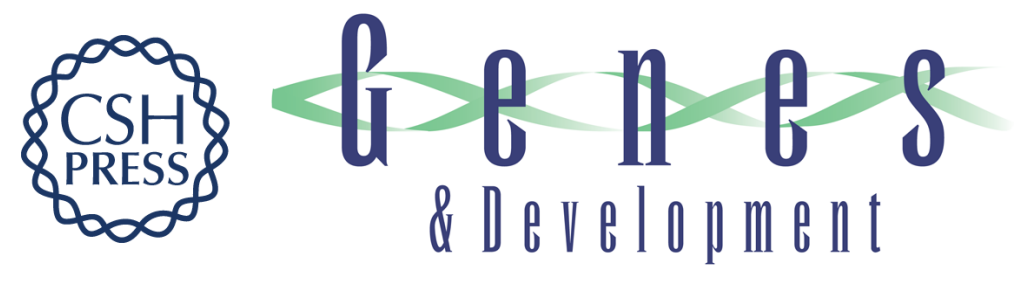

\section{Unraveling the crucial roles of Meis1 in leukemogenesis and normal hematopoiesis}

Bob Argiropoulos, Eric Yung and R. Keith Humphries

Genes Dev. 2007, 21:

Access the most recent version at doi:10.1101/gad.1619407
Related Content Meis1 is an essential and rate-limiting regulator of MLL leukemia stem cell potential Piu Wong, Masayuki Iwasaki, Tim C.P. Somervaille, et al.
Genes Dev. November , 2007 21: 2762-2774
References This article cites 46 articles, 28 of which can be accessed free at:
http://genesdev.cshlp.org/content/21/22/2845.full.html\#ref-list-1
Articles cited in:
http://genesdev.cshlp.org/content/21/22/2845.full.html\#related-urls
License
Email Alerting
Service $\begin{aligned} & \text { Receive free email alerts when new articles cite this article - sign up in the box at the top } \\ & \text { right corner of the article or click here. }\end{aligned}$

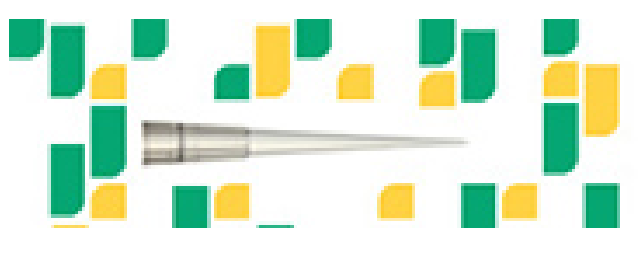

Focused on your science. 